\title{
The urinary phenolic acid profile varies between younger and older adults after a polyphenol-rich meal despite limited differences in in vitro colonic catabolism
}

\author{
Areej Alkhaldy ${ }^{1,2} \cdot$ Christine A. Edwards $^{1} \cdot$ Emilie Combet $^{1}$ (I)
}

Received: 14 July 2017 / Accepted: 26 January 2018 / Published online: 27 February 2018

(c) The Author(s) 2018. This article is an open access publication

\begin{abstract}
Purpose To investigate whether age influences colonic polyphenol metabolism.

Methods Healthy participants, younger $(n=8 ; 23-43$ years) and older $(n=13 ; 51-76$ years), followed a 3-day low-polyphenol diet (LPD) and a 3-day high-polyphenol diet (HPD). Urinary phenolic acids (PA), short chain fatty acids (SCFA), pH and gas were monitored, alongside selected colonic bacteria. Human faecal in vitro fermentations of rutin with or without raftiline were used to evaluate the gut microbiota capacity in a subset of both groups.

Results Total urinary PA were higher in the older group after HPD compared to the younger group (1.5-fold; $p=0.04$ ), with no difference between groups in terms of a change between diets ( $\Delta$ high-low diet). While 17 PA were detected in all younger participants after HPD, a narrower range ( $n=8$ to $16 \mathrm{PA})$ was detected in most $(n=9 / 13)$ older participants, with lower level of benzoic acid (19-fold; $p=0.03$ ), vanillic acid (4.5-fold; $p=0.04$ ) but higher hippuric acid (2.7-fold; $p=0.03$ ). Faecal SCFA concentration did not change after HPD within group, with similar differential excretion ( $\Delta$ high-low diet) between groups. There were no differences between groups for faecal $\mathrm{pH}$, total, faecal bacteria including Flavonifractor plautii, bifidobacteria, and bacteroides. In human in vitro faecal fermentations, seven PAs were detected in both groups after $24 \mathrm{~h}$ of rutin fermentation, with no quantitative and modest qualitative differences between groups. Total SCFA in faecal fermentation did not differ between groups, except for butyric acid (twofold higher in the older group; $p=0.009$ ) when rutin was fermented with raftiline over $24 \mathrm{~h}$.

Conclusions Urinary phenolic acids were less diverse in older participants despite limited difference in functional capacity of in vitro faecal fermentations.
\end{abstract}

Keywords Ageing $\cdot$ Colon $\cdot$ Metabolism $\cdot$ Microbiota $\cdot$ Polyphenols $\cdot$ Inter-individual variability $\cdot$ Gut $\cdot$ Fermentation $\cdot$ Phenolic acid · Age

Electronic supplementary material The online version of this article (https://doi.org/10.1007/s00394-018-1625-1) contains supplementary material, which is available to authorized users.

Emilie Combet

Emilie.combetaspray@glasgow.ac.uk

1 Human Nutrition, School of Medicine Dentistry and Nursing, College of Medical Veterinary and Life Sciences, University of Glasgow, New Lister Building, Glasgow Royal Infirmary, Alexandra Parade, Glasgow G31 2ER, UK

2 Clinical Nutrition Department, Faculty of Applied Medical Sciences, King Abdulaziz University, Jeddah, Saudi Arabia

\section{Introduction}

The number of adults aged 60 years and over will double between 2000 and 2050, from 11 to $22 \%$ [1] globally. The increase in lifespan has a direct effect on the incidence of age-related diseases, including colorectal cancer (CRC), which can put a tremendous strain on health services [2].

The importance of the role of the gut microbiota in health has been increasingly demonstrated. The composition of the colonic microbiota is altered in the elderly with potentially beneficial species, such as Bifidobacteria, Bacteroides, and Lactobacilli declining, and potentially harmful bacteria, such as Escherichia coli, Enterobacteriaceae and Clostridium perfringens, increasing [3]. 
Changes in the colonic microbiota and its metabolic products including short chain fatty acids (SCFA), butyrate, acetate and propionate, could directly affect the proliferation, differentiation, and gene expression of the colonic epithelium [4-6]. Butyrate is the primary energy source for colonocytes, and may play a key role in maintaining homeostasis of the colonic mucosa inhibiting proliferation and inducing apoptosis and differentiation in colorectal cancer cell lines $[7,8]$.

Plant foods contain a large range of bioactive molecules, including (poly)phenolics. The conversion of the parent (poly)phenolic compound (poorly bioavailable) to smaller phenolic acids (with increased bioavailability) by the colonic microbiota is likely to be an important contributor to the beneficial effect ascribed to the compounds.

There is an emerging body of work on the potential impact of (poly)phenolic metabolites on age-related factors (inflammation, oxidative stress, glycation, dysbiosis) contributing to chronic diseases such as CRC [9-14]. Recently, the International Scientific Association for Probiotics and Prebiotic expanded the definition of the prebiotics to include (poly)phenolics as they are selectively metabolised by gut microbiota and release microbial bioactive molecules (including phenolic acids) that may confer local and systematic health benefits [15]. The interactions between the gut microbiota and (poly)phenols have been described in two ways: (1) some (poly)phenols metabolites have the capability to promote and/or inhibit the growth certain bacteria [16] and (2) the gut microbiota contributes to the production of small potentially bioactive molecules including phenolic acids [17]. (Poly)phenolics may have protective effects in the gastrointestinal tract by: (1) inhibiting the growth of pathogenic species, e.g. Clostridium spp, Staphylococcus aureus, and Bacteroides spp. [18]; (2) suppressing the adhesion of gut pathogens to human gut cells [19]; (3) enhancing natural killer cell activity and cytokine secretion [20]. In older adults (40-50 years old), a higher urinary concentration of phenolic metabolites of anthocyanin such as syringic acid, $p$-coumaric acid, 4-hydroxybenzoic acid, and homovanillic acid was associated with higher bifidobacteria level ( $>4.47$ vs. $<1.18 \log { }^{10}$ copies per g faeces) [17].

Research into the bioavailability and metabolism of (poly)phenols, has so far been mostly limited to young adults [21-26], and inter-individual factors likely to impact on the outcome measures have rarely been studied in depth [27-33]. One study, in particular, looked at the effect of ageing on the absorption, metabolism, and excretion of epicatechin in healthy younger and older subjects after the consumption of cocoa flavanols, with little difference observed between subjects; the study did not, however, consider the colonic metabolism of epicatechin, or phenolic acids production [34]. As a result, very little is currently known about the impact of ageing on the metabolic fate of (poly) phenolics in the human gastrointestinal tract, despite the fact that age is a key risk factor for a non-communicable disease development.

As the body ages, several changes may influence the bioavailability and colonic bacterial metabolism of plant (poly) phenolics: (1) longer transit times [35]; (2) increase in conditions such as irritable bowel syndrome, diverticulosis, and colon cancers which are linked with changes in gut microbiota [36-39]; (3) reduced chewing strength, leading to different food choices and lower fibre intake [40]; (4) reduced physical activity which may affect gut function including frequency of bowel movements [41], (5) changes in the composition/diversity of the microbiota [3]. As the majority of (poly)phenolics are metabolised by bacterial enzymes in the colon, this may influence their colonic metabolism.

As there are very limited data on the effect of ageing on the bacterial metabolism of (poly)phenols, this study aimed to test whether age ( $\geq 50$ years) affects the colonic metabolism of dietary (poly)phenolics, with a focus on flavonols, which are ubiquitous in the Western diet. Rutin was used as a "model" flavonol as it is a well-characterised molecule with published evidence related to its breakdown. Rutin is a quercetin glycoside, which resists hydrolysis and is not deglycosylated within the human small intestine by cytosolic $\beta$-glucosidase and/or the lactase-phlorizin hydrolase enzymes, and thus pass intact to the large intestine. Rutin is degraded in the colon by the microbiota to low molecular weight, phenolic acids, and is a well-characterised molecule $[22,23]$. We hypothesized that the colonic metabolism of (poly)phenols would be less efficient in older adults.

\section{Methods}

\section{Study design}

Two designs were utilised to test the study hypothesis. The first employed a human dietary intervention to compare the colonic metabolism of (poly)phenols between healthy younger $(<45$ years) and older ( $>50$ years) adults, focusing on urinary phenolic acid excretion and gut bacterial composition (focusing on known polyphenol-degrading bacteria). The age cut-off, while arbitrary, was designed to obtain two groups distinct in age. The National Health Service in Scotland uses the age of 50 years as the cut-off for their bowel screening programme, justified by the increased risk of colonic diseases in this age group [42]. The second design employed an in vitro fermentation model, using faecal samples collected during the dietary intervention, to study the metabolic (functional) capacity of the faecal microbiota according to age when a specific flavonol, rutin (quercetin-3-O-rutinoside), was fermented. 


\section{Subjects and recruitment}

Older ( $\geq 50$ years) and younger $(<45$ years) adults were recruited using local advertisements, printed poster displays, and online social networking sites. Exclusion criteria included consuming alcohol ( $>4$ units/day), obesity (BMI $>30 \mathrm{~kg} / \mathrm{m}^{2}$ ), taking dietary supplements, pregnancy or risk of pregnancy, smoking, taking any medication, or having any conditions known to affect bowel function. Approval for this study was obtained from the Ethics committee of the University of Glasgow, College of Medical; Veterinary \& Life Sciences (ref FM03110). All participants gave informed written consent.

\section{Sample size and power calculation}

The sample size was calculated with GPower version 3.1 (Dusseldorf university) using urinary phenolic acid excretion as a primary outcome. In younger adults [43], selected urinary phenolic acid excretion increased from $20.6 \pm 7.6$ to $62.7 \pm 44.3 \mu \mathrm{mol} /$ day after a high-polyphenol diet ( $\Delta$ highlow diet $42.2 \pm 41.0$ ). Pilot analyses showed that excretion varied between ethnic subgroups, with a difference for the $\Delta$ high-low diet of $59 \mu \mathrm{mol} /$ day between groups (Caucasian $\Delta$ high-low $60.5 \pm 36.0 \mu \mathrm{mol} / \mathrm{day} ;$ Asian $\Delta$ high-low diet $1.5 \pm 10.2 \mu \mathrm{mol} /$ day; groups with unmatched numbers $d=1.6$ ). Assuming a similar effect size of $d=1.6$, a total of $n=16$ participants is sufficient to detect (or not) a similar difference ( $\beta=80 \%$, two tails, $\alpha=0.05$ ). Based on previous experience with similar trials, we allowed for a $40 \%$ dropout rate to recruit a sample of $n=13$ individuals per group. While recruitment in the older group reached $n=13$, this was not the case for the younger group $(n=8)$-as such, the a priori power of the study to detect an effect size of 1.33 is $80 \%$ (and $92 \%$ for $d=1.6$ ) given the sample size and allocation.

\section{Measurements and sample collection}

Anthropometric measurements height, weight, body mass index (BMI), and waist circumference (WC), and blood pressure (BP) were collected at baseline and all subsequent appointments using standard techniques [44]. All participants followed two 3-day diets separated by a 1 week washout: a low-polyphenol diet (LPD, avoiding all fruits, vegetables, onions, coffee, tea, chocolate, vanilla and similar flavourings, whole meal products, alcohol, spices, and all dietary supplements) and a high-polyphenol diet (HPD, including flavonoid-rich foods including tomatoes, plums, provided along with cooking guidance and recipes) (Supplementary Table 1). The phenolic composition and fibre content of the HPD are available in Supplementary Table 2. Urine ( $24 \mathrm{~h}$ ) was collected on the last day of each diet, and a morning stool sample was collected at the end of the 3-day diet.

\section{Bowel movements}

The usual frequency of bowel movements (twice daily or more, daily, every 2-3 days or less than twice a week) was self-reported retrospectively at the beginning of the study.

\section{Dietary assessment of (poly)phenol intake}

Prospective, weighed dietary records were kept by participants throughout each study period. Diaries were analysed using the WinDiets Nutritional Analysis Software (Robert Gordon University, Aberdeen, UK) [45]. The mean flavonoid content of foods was sourced from the Phenol-Explorer database (http://www.phenol-explorer.eu/contents) [46]. The flavonoid content of low-polyphenol foods such as pasta, bread, biscuits, cakes and pastry was estimated from their wheat flour content [47].

\section{In vitro fermentation (faecal incubation)}

The faecal incubation was prepared as previously described [48]. The substrates used were (a) control (no substrate), (b) $28 \mu \mathrm{M}$ rutin, and (c) $28 \mu \mathrm{M}$ rutin (Sigma-Aldrich Company Ltd; Dorset, UK) with $1 \mathrm{~g}$ raftiline HP (Orafti, Tienen, Belgium). Raftiline (fibre) was added to the fermentation medium as a source of energy (carbon) to help mimic in vivo conditions (compared to fermentations without a source of carbon or a fast-fermented source such as glucose).

Freshly voided human faecal samples were homogenised with sodium phosphate buffer $(0.1 \mathrm{M}, \mathrm{pH} 7.0)$ in a blender (Braun $^{\mathrm{TM}}$ ) to make a $32 \%$ faecal slurry (16 g faecal sample with $50 \mathrm{ml}$ sodium phosphate buffer). The faecal slurry ( $5 \mathrm{ml}$ ) was added to $44 \mathrm{ml}$ of fermentation medium in $100 \mathrm{ml}$ glass sterilised bottles. The substrate (rutin, $28 \mu \mathrm{mols}$ ) was added to the faecal slurry with or without $1 \mathrm{~g}$ of a highly fermentable fibre (raftiline). Control cultures containing no substrates were incubated at the same time. Participants were asked to provide a whole bowel movement, and the same sample was used to produce the faecal slurry added to the four fermentation bottles (a single bottle for each condition). The anaerobic conditions were established by using anaerobic reagents in the media (reducing solution checked with resazurin) and by flushing the media and bottles with oxygen-free nitrogen. The fermentation bottles were sealed with a gas-tight septum, which was fitted with a gas collection syringe monitoring gas production. Fermentation bottles were kept upright in a shaking water bath at $37^{\circ} \mathrm{C}$, 60 strokes/min for $24 \mathrm{~h}$ to simulate the colonic lumen conditions. Two samples $(3 \mathrm{ml})$ of fermentation fluid were collected after 0, 2, 4, 6 and $24 \mathrm{~h}$. One sample for each time 
point was immediately stored at $-80{ }^{\circ} \mathrm{C}$ for phenolic acid analysis. The other was mixed with $1 \mathrm{M} \mathrm{NaOH}(1 \mathrm{ml})$ and stored at $-20{ }^{\circ} \mathrm{C}$ for SCFA production measurements.

\section{Colonic fermentation markers: $\mathrm{pH}$ and gas production}

A 50-ml disposable syringe and a three-way tap were used to measure gas production in each fermentation bottle at different time points $(0,2,4,6,24 \mathrm{~h})$. An auto-calibrated portable digital $\mathrm{pH}$ meter model (Hanna pH20 instruments, USA) was used to measured faecal $\mathrm{pH}$ by preparing a suspension of $\sim 1 \mathrm{~g}$ faecal sample from each participant and diluted in $3 \mathrm{~mL}$ of distilled water. The $\mathrm{pH}$ of fermentation fluid was determined at $0,2,4,6$, and $24 \mathrm{~h}$ with universal $\mathrm{pH}$ indicator paper from 1 to 14 (Fisher Brand, UK).

\section{Phenolic acid extraction, derivatization and analysis by gas chromatography mass spectrometry (GC-MS)}

Phenolic acids were measured in urine and fermentation fluid. Extraction and derivatisation were carried out as previously described [43]. Derivatized phenolic acids were analysed on a Trace GC interfaced to a DSQ mass spectrometer equipped with a split/splitless injector and an AI3000 autosampler (Thermo Fisher, Hemel Hempstead, UK) as previously described [42]. Identification of phenolic acids was based on retention time $\left(t_{\mathrm{R}}\right)$ and target ions [49]. Quantification was based on 2.5 to $15 \mu \mathrm{g}$ calibration curves of derivatised and analysed phenolic acid standards. The area ratio of each standard was averaged and the coefficient of variance calculated $\left(R^{2}>0.98\right)$.

\section{SCFA analysis by gas chromatography with flame ionization detection (GC-FID)}

Short chain fatty acids were measured in dry faeces and fermentation fluid. Extraction and analysis were carried out according to Laurentin and Edwards [50]. SCFAs were estimated using a TRACETM 2000 gas chromatograph (Thermo Quest Ltd, Manchester, UK) equipped with a flame ionization detector $\left(250^{\circ} \mathrm{C}\right)$ and a Zebron ZB-Wax capillary column $(15 \mathrm{~m} \times 0.53 \mathrm{~mm}$ id $\times 1 \mu \mathrm{m}$ film thickness, catalogue No.7 EK-G007 22, Phenomenex, Cheshire, UK). EK-G007 22, Phenomenex, Cheshire, UK).

\section{Extraction, concentration, and purity of bacterial DNA}

Bacterial DNA was isolated and purified as previously described [51]. DNA concentration and purity were determined by measuring $1.5 \mu \mathrm{l}$ of undiluted DNA extract with a NanoDrop ND-1000 (software version 3.7.4; Fisher
Scientific, UK). An absorbance ratio (A260/A280) greater than 1.8 was used to assess high purity, and the absorbance ratio at 230/260 $\mathrm{nm}$ was used to assess guanidinium salt carried. Furthermore, DNA was assessed for shearing by electrophoresis.

\section{Determination of bacterial diversity and composition}

Flavonifractor plautii was selected for quantification in faecal samples because of its previous reported contribution to the colonic metabolism of flavonoids [52-54]. Bifidobacteria, bacteroides, and total bacteria were also measured. Realtime PCR with species-specific probes was used to quantify individual species, bacterial populations, and total bacteria (Supplementary Methods) on a 7500 Real-Time PCR System (Applied Biosystems, Carlsbad, CA) using TaqMan. Quantification was performed against serial dilution of bacterial DNA standards obtained from pure cultures (Supplementary Methods). DNA standards for F. plautii (DSM 4000; $6.3 \mathrm{ng} / \mu \mathrm{l})$ were obtained from the German Collection of Microorganisms and Cell Cultures (DSMZ). Standard DNA for bifidobacteria (Bifidobacterium longum, DSM 20219T, $9.8 \mathrm{ng} / \mu \mathrm{l}$ ), bacteroides [Bacteroides vulgatus (DSM 1447T, $27.2 \mathrm{ng} / \mu \mathrm{l}$ )], and total bacteria [Bacteroides vulgatus (DSM $1447 \mathrm{~T}, 27.2 \mathrm{ng} / \mu \mathrm{l})$ ] were available in-house [51]. A set of seven bacterial reference standards were prepared for each target. The serial dilution to measure the Eubacterium ramulus and F. plautii was 1:5, and 1:10 to measure bifidobacteria, bacteroides, and total bacteria.

\section{Statistical analysis}

Data were analysed using Minitab 16. The Anderson-Darling test was used for normality. Descriptive statistics are presented as mean and standard deviation, or medians and inter quartile range (IQR). Comparisons between groups were carried out using Mann-Whitney test for non-parametric data and paired test and two sample $t$ tests for normally distributed data. Chi-squared test was used to compare the frequency of bowel movement between groups.

\section{Results}

\section{Subject characteristics}

13 older adults aged between 51 and 76 years old and eight younger adults aged between 23 and 43 years old were recruited, with no subsequent drop-out. The baseline data for participants are presented in Table 1, with no significant differences in anthropometric characteristics between the two groups. Median BMI and WC were within the normal 
Table 1 Baseline data in younger $(n=8)$ and older $(n=13)$ participants

\begin{tabular}{|c|c|c|c|c|c|}
\hline & \multicolumn{2}{|c|}{ Younger group $(n=8)$} & \multicolumn{2}{|c|}{ Older group $(n=13)$} & \multirow[t]{2}{*}{$p$ value } \\
\hline & Median & IQR & Median & IQR & \\
\hline Age (years) & 23.0 & $22.0-28.5$ & 61.0 & $54.0-64.0$ & 0.0002 \\
\hline Height $(\mathrm{cm})$ & 163.0 & $155.3-174.3$ & 161.0 & $1.6-1.7$ & 0.3 \\
\hline Weight (kg) & 63.0 & $56.4-69.8$ & 63.0 & $59.4-75.7$ & 0.4 \\
\hline $\operatorname{BMI}\left(\mathrm{kg} / \mathrm{m}^{2}\right)^{\mathrm{a}}$ & 22.0 & $20.6-26.4$ & 25.1 & $23.8-28.4$ & 0.06 \\
\hline $\mathrm{WC}(\mathrm{cm})^{\mathrm{b}}$ & 80.0 & $77.8-80.8$ & 85.0 & $79.0-98.0$ & 0.1 \\
\hline Systolic BP & 122.0 & $108.5-127.5$ & 120.0 & $117.0-137.0$ & 0.2 \\
\hline \multirow[t]{2}{*}{ Diastolic BP } & 69.0 & $59.8-73.5$ & 86.0 & $75.0-89.0$ & 0.005 \\
\hline & $n$ & $\%$ & $n$ & $\%$ & \\
\hline $\operatorname{Sex}(M / F)$ & $2 / 6$ & - & $3 / 10$ & - & $0.99 *$ \\
\hline Normal weight & 5 & 62.5 & 6 & 46.1 & $0.68 *$ \\
\hline Overweight & 3 & 37.5 & 7 & 53.8 & - \\
\hline Obese & 0 & 0 & 0 & 0 & - \\
\hline
\end{tabular}

* $p$ value using Fisher's exact test between age group

${ }^{a}$ BMI cut-off points of overweight [adult $=25$, older adult $(55-65$ years old $\left.)=28\right]$; [55, 56]

${ }^{b} \mathrm{WC}$ cut-off points of high risk (adult women $=80 \mathrm{~cm}$, men $=94 \mathrm{~cm}$; older women $=99 \mathrm{~cm}$, men $=106 \mathrm{~cm}$ ); $[55,56]$

cut-off range for younger and older healthy adults. The male to female ratio was similar between groups, with two males and six females in the younger group and three males and ten females in the older adult group $(p=0.99)$. Diastolic BP was higher (by $17 \mathrm{mmHg}$ ) in older adults $(p=0.005)$.

Frequency of bowel movements was not different between younger and older groups $(p=0.84)$ with $37.5 \%$ in the younger group and $25 \%$ in the older group having twice daily or more frequent bowel movement; $37.5 \%$ in the younger group and $50 \%$ in the older group having daily bowel movement; and $25 \%$ in the younger group and $25 \%$ in the older group having a bowel movement every 2-3 days.

\section{Flavonoid intake during low- and high-polyphenol diets (LPD and HPD)}

Flavonoid intake during the 3-day LPD was $6 \mathrm{mg} /$ day in the younger (IQR 2-10) and older groups (IQR 2-16). During the 3-day HPD, flavonoid intake in younger adults was $510 \mathrm{mg} /$ day (IQR 499-539) and $496 \mathrm{mg} /$ day (IQR 438-540) in older adults. Flavonoid intake increased from low to high diet for both groups $(p=0.000)$, with no difference between groups (Fig. 1). Moreover, there were no differences between the groups in term of flavonols or phenolic acids intake after the HPD (Supplementary Table 3). As urinary phenolic acid excretion has been shown to be markedly increased between 8 and 24 h following ingestion [31], urinary phenolic acid excretion was corrected for flavonoid intake on day 3 of the diet, given that the $24 \mathrm{~h}$ urine collection was carried out from the second urine of day 3 , and including the first urine of day 4.
There was no difference between groups for intake on day 3, during the LPD [5 mg (IQR 2-10) versus $9 \mathrm{mg}$ (IQR 5-21) for younger and older groups, respectively] or the HPD [553 mg (IQR 474-666) versus 497 mg (IQR 305-643) for younger and older groups, respectively].

\section{Dietary fibre intake during low- and high-polyphenol diets (LPD \& HPD)}

The fibre intake increased after the HPD in both groups (younger: $p=0.0009$; older: $p=0.002$ ) with no difference between groups in terms of change to dietary fibre intake $(p=0.6)$. Dietary fibre intake during the 3-day LPD was $9 \mathrm{~g} /$ day (IQR 8-10) in the younger and $12 \mathrm{~g} /$ day in the older group (IQR 8-14). During the 3-day HPD, dietary fibre intake in younger adults was $27 \mathrm{~g} /$ day (IQR 26-29) and $27 \mathrm{~g} /$ day (IQR 24-34) in older adults (Supplementary table 4).

\section{Macronutrient/ micronutrient intake during low- and high-polyphenol diets (LPD and HPD)}

There was no difference between groups in terms of energy, fat, protein, carbohydrate, total sugars, starch, or alcohol intake during either low or HPD, or when considering the difference in macronutrient intake between dietary periods ( $\Delta$ high-low diet) (Supplementary Table 4). The intake of vitamins or dietary minerals did not differ either, except for thiamine and copper intake during the HPD, with thiamine intake higher (1.3-fold; $p=0.05)$ in the older group, and copper intake higher $(1.4$-fold; $p=0.01)$ in the younger group (Supplementary Table 5). 


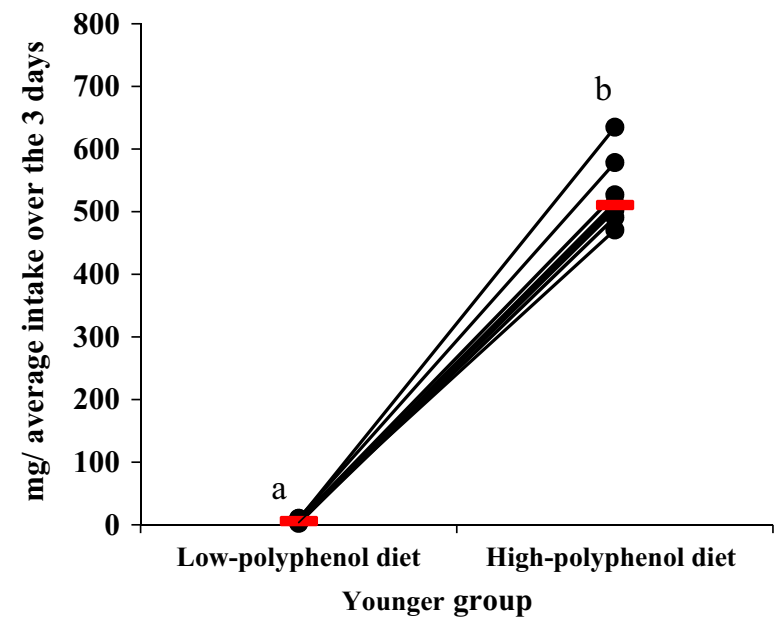

Fig. 1 Average flavonoid intake over the 3 days low- and high-polyphenol diets in younger $(n=8)$ and older $(n=13)$ participants. Each circle indicates the estimated average daily flavonoid intake for each

\section{Identification of phenolic acids in urine}

A total of 18 urinary phenolic acids were identified and quantified by GC-MS after LPD and HPD in the younger group. However, 4-OHPAA was excluded from the sum of urinary phenolic acid excreted for between-group comparisons, as it is produced by pathways unrelated to the colonic degradation of (poly)phenols [31] and did not increase in young or older adults after the HPD. Subsequently, only $n=17$ phenolic acids are reported (Table 2).

\section{Urinary phenolic acid excretion after low- and high-polyphenol diets (LPD and HPD)}

The sum of the 17 urinary phenolic acids excreted increased $\sim 5.6$-folds in the younger group from $205 \mu \mathrm{mol} /$ day (IQR 158-525) after the LPD to $1197 \mu \mathrm{mol} /$ day (IQR 730-1345) after the HPD $(p=0.0009)$, and $\sim 5.5$-fold in the older group, from $336 \mu \mathrm{mol} /$ day (IQR 190-469) to $1819 \mu \mathrm{mol} /$ day (IQR 986-2831) respectively $(p=0.0002)$. The change in urinary excretion ( $\Delta$ high-low diet) was not different between groups; however, the urinary phenolic acid excretion was higher after the HPD in the older group $(p=0.04)$ compared to the younger group (Fig. 2), with a large variability in urinary PA excretion in the older group. Correcting for flavonoid intake did not reveal further difference in differential excretion between the groups. Based on the key (statistical) differences seen between LPD and HPD, the main phenolic acids linked to rutin metabolism that are excreted in urine, by at least threefold, are 3-OHPAA, HVA, 3,4DOHPAA, 3,4 DIOHPPA, and 3-OHhippA.

Hippuric acid (HA) was always the most abundant acid in urine samples in both groups ( 80 and $98 \%$ of total phenolic

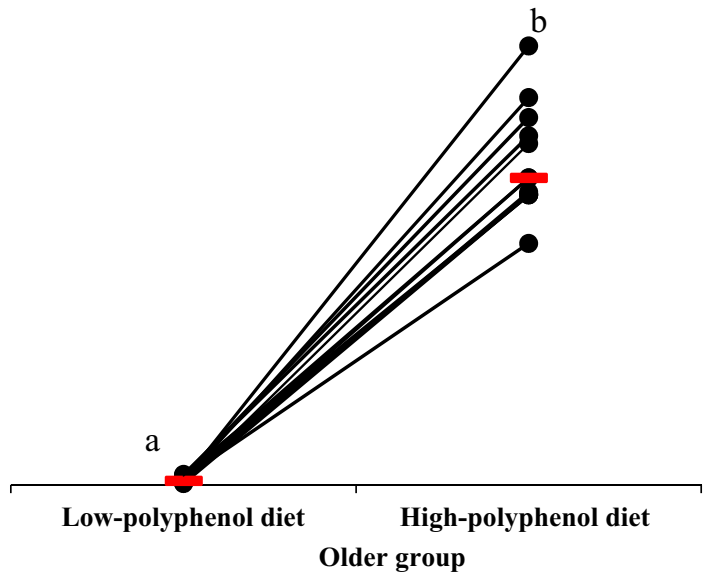

participant after low- and high-polyphenol diets. Median flavonoid intake for each group is indicated by a red horizontal line. a, b symbols indicate differences within group (LPD to HPD; $p=0.000$ )

acids for younger and older groups, respectively), and was higher in the older group after the HPD (2.7-fold; $p=0.03$ ) compared to LPD. However, the change in excretion, $\Delta$ highlow diet, was not different between groups.

The sum of urinary phenolic acids minus HA was considered (as HA is most likely to be formed in the liver by conjugation of benzoic acid and glycine, rather than from flavonoid metabolism). The sum of PA excreted after the HPD increased in both groups (compared to LPD), twofold in the younger group, from $104 \mu \mathrm{mol} / \mathrm{day}$ (IQR 91-129) to $211 \mu \mathrm{mol} / \mathrm{day}$ (IQR 146-233) $(p=0.003)$ and in the older group, from $56 \mu \mathrm{mol} /$ day (IQR $48-77$ ) to $100 \mu \mathrm{mol} /$ day (IQR 78-127) $(p=0.007)$. The difference in urinary excretion $(\Delta$ high-low diet) remained similar between groups. However, urinary phenolic acid concentration was higher after the LPD $(p=0.03)$ and HPD in the younger group $(p=0.02)$; Fig. 3 .

Most notably, there were important qualitative and quantitative differences between groups for the excretion of individual phenolic acids ( $\Delta$ high-low diet). While 17 phenolic acids were identified in all younger participants after both diets, only eight phenolic acids were excreted by all older participants (BA, MA, 3-OHPAA, HVA, 4-OHMA, 3,4diOHPAA, HA, 3-OHhippA) (Table 2). A narrower range of urinary phenolic acids $(n=8-16)$ was detected in most $(n=9 / 13)$ older participants. The older group excreted 19-fold less BA $(p=0.03)$, and 4.5-fold less VA $(p=0.04)$ than the younger group (Table 2).

\section{Faecal pH after low- and high-polyphenol diets (LPD and HPD)}

After the HPD, the faecal $\mathrm{pH}$ significantly decreased in the older group from 7.7 (IQR 7.4-7.9) to 6.9 (IQR 6.7-7.4; 


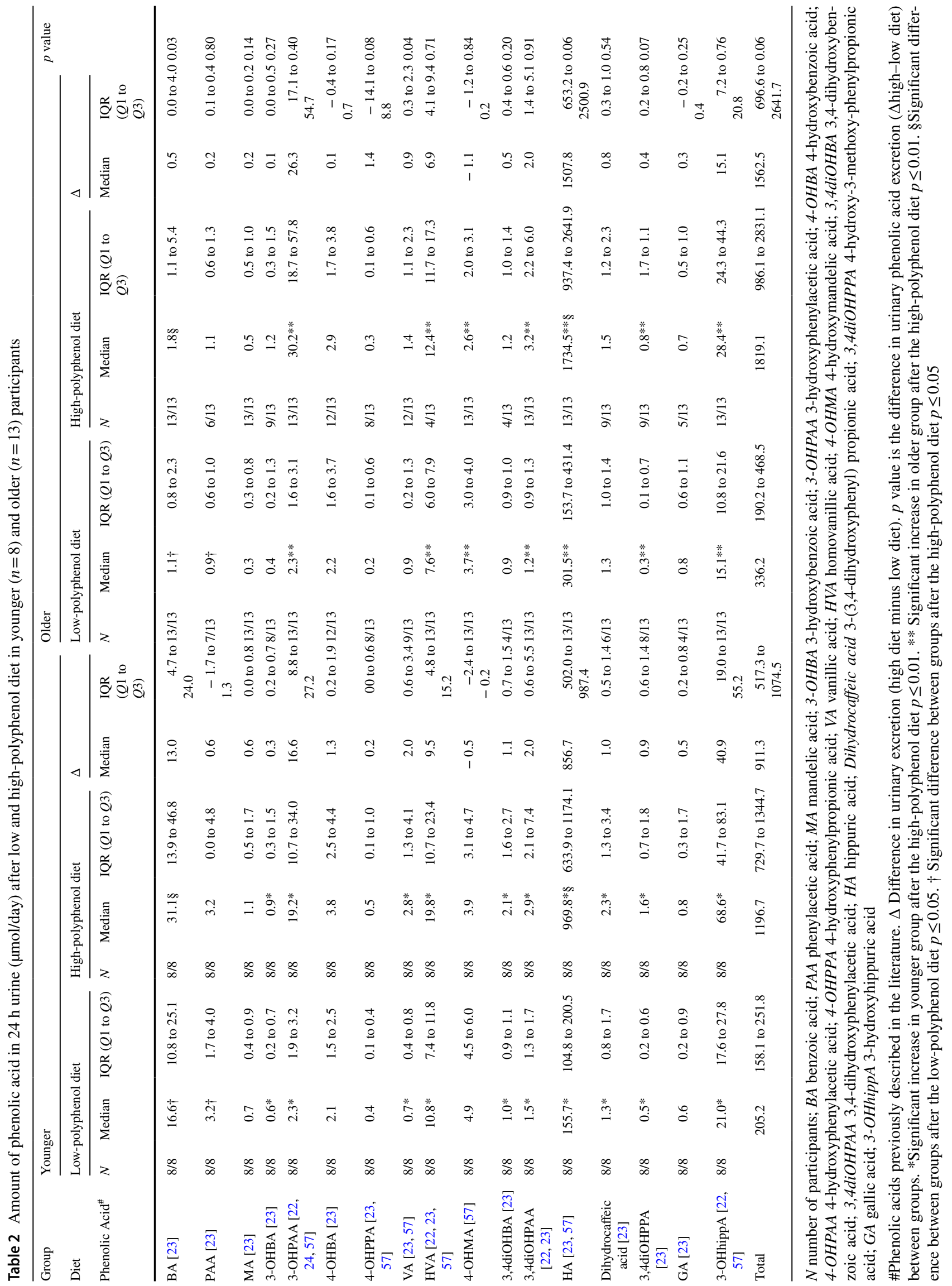



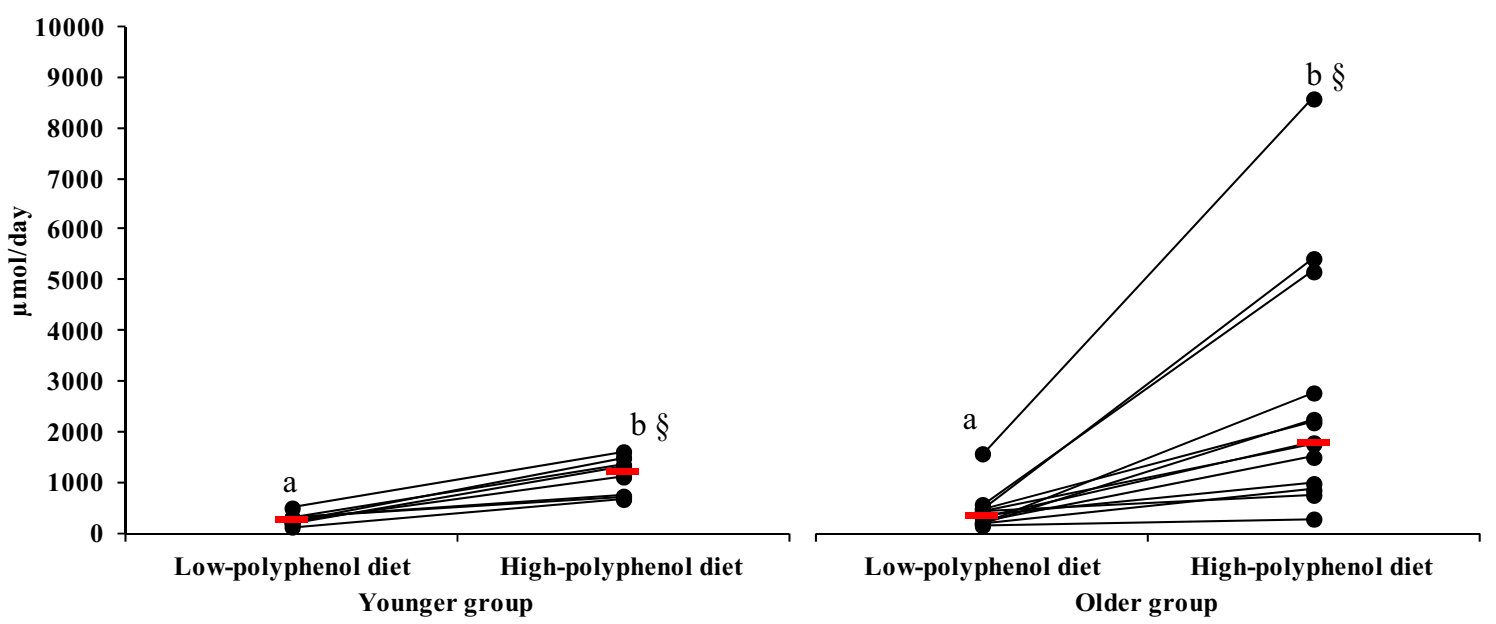

Fig. 2 24-hour urinary phenolic acid profile excretion ( $\mu \mathrm{mol} /$ day) after low and high-polyphenol diets in younger $(n=8)$ and older $(n=13)$ participants. Each circle indicates the measurement of the urinary phenolic acids profile for each participant after low and highpolyphenol diets. Median urinary phenolic acids for each group are

indicated by a red horizontal line. a, b symbols indicate differences within group (LPD to HPD; younger: $p=0.0009$; older: $p=0.0002$ ). $\S$ Symbol indicates differences between groups (HPD vs. HPD; $p=0.04)$

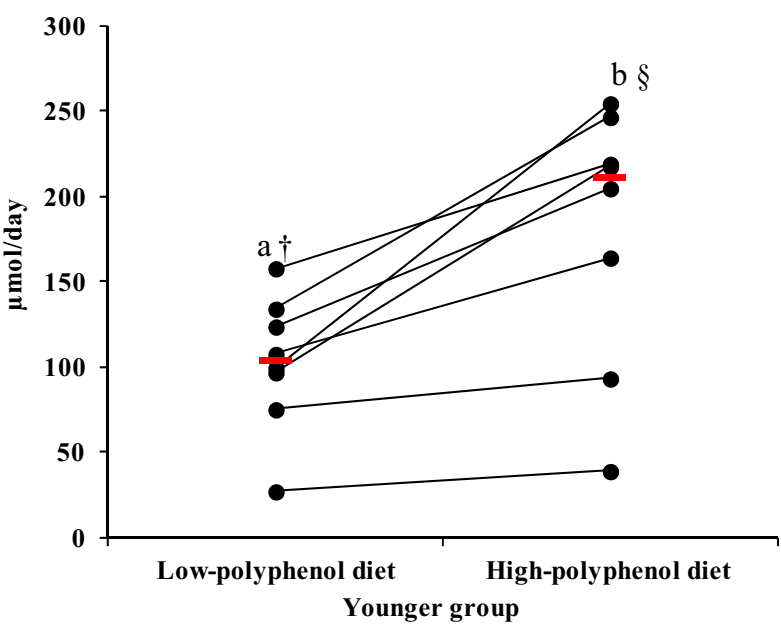

Fig. 3 24-hour urinary phenolic acid profile excretion without hippuric acid ( $\mu \mathrm{mol} / \mathrm{day})$ after low- and high-polyphenol diets in younger $(n=8)$ and older $(n=13)$ participants. Each circle indicates the measurement of the urinary phenolic acids profile without hippuric acid for each participant after low- and high-polyphenol diets. Median urinary phenolic acids profile without hippuric acid for each group

$p=0.006)$, but not in the younger group (7.2, IQR 6.9-7.5 to 6.7, IQR 6.4-7.1). Looking at $\mathrm{pH}$ changes with $\operatorname{diet}(\Delta$ high-low diet for $\mathrm{pH}$ ), there was no significant difference between the groups (Supplementary Fig. 1).

\section{Faecal SCFA after the low- and high-polyphenol diets (LPD and HPD)}

Total faecal SCFA concentration (sum of all SCFA) did not change significantly from low to HPD in either group

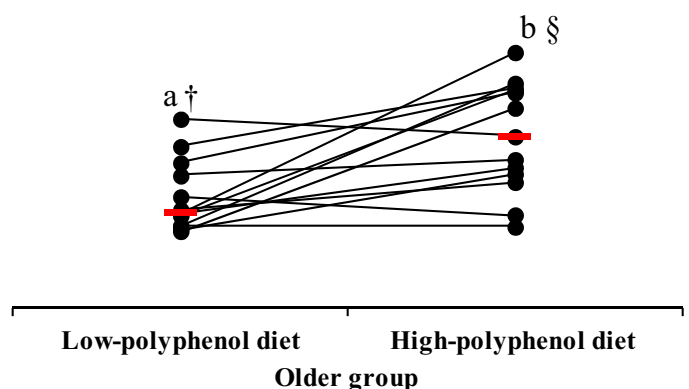

is indicated by a red horizontal line. a,b symbols indicate differences within group (LPD to HPD; younger: $p=0.003$; older: $p=0.007$ ). $\dagger$ Symbol indicates differences between groups (LPD vs. LPD; $p=0.03$ ). §Symbol indicates differences between groups (HPD vs. HPD; $p=0.02$ )

despite a threefold increase in fibre intake [younger from $164 \mu \mathrm{moles} / \mathrm{g}$ dwt (IQR 124-218) to $192 \mu$ moles/g dwt (IQR 162-214); older from $258 \mu$ moles/g dwt (IQR 168-280) to $265 \mu$ moles/g dwt (IQR 208-301)]. Although there were no significant differences ( $\Delta$ high-low diet) between the groups, the mean SCFA concentration was 1.4 fold higher in the older group compared to the younger group after the HPD ( $p=0.01$; Supplementary Fig. 2$)$. There were no differences in the changes ( $\Delta$ high-low diet) in each specific acid between groups. However, the absolute levels of acetic 
acid were higher after both the LPD (1.5-fold; $p=0.01)$ and HPD (1.4-fold; $p=0.02$ ) in the older group, compared to the younger group. Absolute levels of heptanoic acid were higher after the HPD in the younger group (1.8-fold; $p=0.03$; Supplementary Table 6).

\section{Concentration of bacterial DNA isolated from faecal samples after LPD and characteristics of the qPCR run condition}

High quality and high yield DNA was obtained from all faecal samples. The purity and yield of the extracted DNA was high (1.7-2.0 absorbance ratio 280/260 nm; yield $463 \mathrm{ng} /$ $\mu \mathrm{L}$ (IQR 429-552) for older group samples, $519 \mathrm{ng} / \mu \mathrm{L}$ (IQR 480-576) for the younger group samples). The faecal DNA appeared intact and compact as a high-molecular-weight band when electrophoresed through a $1.5 \%$ agarose gel. The qPCR amplification efficiency was within the normal range (90-105\%) for the total bacteria, Bacteroides-Prevotella, and Flavonifractor plautii in both groups; however, efficiency for Bifidobacterium spp. was just below the normal range (87\%) in both groups. The coefficient of determination $\left(R^{2}\right)$ range was between 0.994 and 0.999 for all bacterial groups and species in both groups. Absolute levels of bifidobacteria, bacteroides, and Flavonifractor plautii did not differ between younger and older groups (Table 3).

\section{In vitro fermentation of rutin}

Ten fermentations were carried out using the stool samples of six younger (one male and five females) and four older subjects (one male and three females), collected after the LPD. Rutin was fermented for $24 \mathrm{~h}$ with or without fibre (raftiline) to test the metabolic capacity of the gut faecal contents, including the microbiota, in relation to ageing. There was no change in the $\mathrm{pH}$ of the fermented faecal fluids containing rutin alone, over time, in either group (Supplementary Fig. 3). However, raftiline and the combination of rutin + raftiline reduced $\mathrm{pH}$ from 7 to 5 by $24 \mathrm{~h}$, in both groups. There was no difference in total gas production between groups after $24 \mathrm{~h}$. In both younger and older groups, the combination of rutin + raftiline increased gas production more than rutin alone ( $p=0.02 ; p=0.03$; respectively). Moreover, the older group produced 1.9-fold more gas over $24 \mathrm{~h}$ fermentation than the younger group when raftiline was fermented alone ( $p=0.02$; Supplementary Table 7).

\section{Metabolism of rutin in faecal fluids and phenolic acids formation}

Seven phenolic acids were detected in fermentations of rutin with faecal samples from younger and older adults,

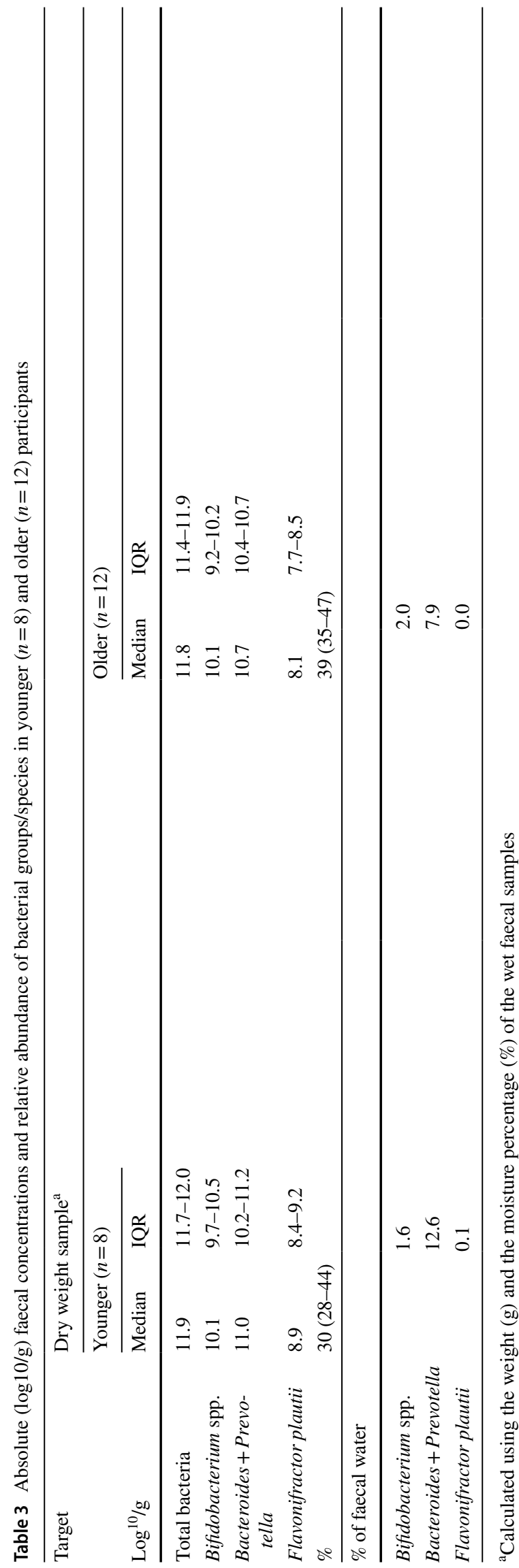


over $24 \mathrm{~h}$, with great variability within and between groups (Table 4).

Only PAA and 3-OHPPA were detected in all fermentations, while 3-OHPAA (younger: 5/6; older 3/4) and 4-OHPPA (younger: 5/6; older 4/4) were detected in most fermentations. 3,4diOHPAA, a recognised rutin metabolite, was seen in all younger donors and most older donors (younger: 6/6; older 3/4). Finally, 4-OHBA (younger: 1/6; older 2/4) and 3,4diOHPPA (younger: 2/6; older 2/4) were detected in the fermentations of some donors only. Five of these phenolic acids were also detected in the control fermentation at $0 \mathrm{~h}$ : PAA was detected in all younger and older donors; however, 4-OHPPA (younger: $2 / 6$; older 3/4), 3-OHPPA (younger: $2 / 6$; older 4/4), 4-OHBA (older only $2 / 4$ ), and 3-OHPAA (younger only $1 / 6$ ) were detected in the fermentations of some donors (Table 4).

The sum of the seven phenolic acids increased over time in all rutin fermentations, with or without raftiline in the younger group (35-fold with rutin only, $p=0.000$, sixfold with rutin + raftiline, $p=0.001$ ) and in the older group when rutin was fermented alone (21-fold, $p=0.04$ ), without significant increase with the addition of raftiline (ninefold change, $p=0.06$ ). There was no difference in the sum of the seven acids between groups after $24 \mathrm{~h}$ in all rutin fermentations, with or without raftiline. The addition of raftiline to the fermentation inhibited the formation of all seven phenolic acids after $24 \mathrm{~h}$, by sevenfold $(p=0.02)$ in the younger group and 2.8 -fold $(p=0.33)$ in the older group with no detectable difference between groups (Fig. 4).

\section{Individual phenolic acids formed after the fermentation of rutin}

PAA increased over time in the fermented faecal fluids from the younger group with rutin ( 25 -fold; $p=0.000$ ) and rutin + raftiline (2.1-fold; $p=0.03$ ), and in the fermented faecal fluids from the older group with rutin only (19-fold; $\mathrm{p}=0.04$ ) but not with the addition of raftline. The older group formed more PAA in the fermentations of rutin + raftiline (threefold; $p=0.01$ ) and raftiline only (fourfold; $p=0.03$ ) compared with the younger group but no differences were detected between groups when rutin alone was fermented. 3-OHPPA also increased in the fermented faecal fluids containing rutin only in both younger (13-fold, $p=0.02$ ) and older (25-fold, $p=0.03$ ) groups, with no differences between the groups (Table 4).

\section{Metabolism of rutin in and SCFA production faecal incubation}

Total SCFA concentrations increased over time in the fermentations of rutin + raftiline (38-fold for the younger group, $p=0.005$; 58 -fold for the older group, $p=0.03$ ) and rutin only (13-fold for younger group, $p=0.005$; 14 -fold for the older group, $p=0.03$ ) with no differences between groups. Acetic and propionic acid did not differ between the groups but butyric acid concentration was higher in the older group (two-fold; $p=0.009$ ) at $24 \mathrm{~h}$ (Supplementary Table 8 ).

\section{Discussion}

This study tested the hypothesis that age influences the metabolism of dietary (poly)phenols, which may be relevant for gut health and the development of chronic diseases. To our knowledge, this is the first dietary semi-controlled study investigating the colonic metabolism of dietary polyphenols in different age groups using human feeding and in vitro faecal fermentation designs. 3 days on each diet was enough for (poly)phenol-rich foods to be supplied to the colon and be fermented over the course of several meals. The present study showed:

1. Inter and intra variability in younger and older groups in terms of urinary excretion of phenolic acids after LPD/ HPD.

2. Limited differences between groups in phenolic acid formation after fermentation of rutin with in vitro batch faecal incubations.

Previous work compared absorption, metabolism, and excretion of epicatechin in healthy younger and older subjects, with limited differences in flavonol metabolites levels in plasma and 24-h urinary collection between the age groups [34]. Our own results align with these findings, showing limited quantitative differences between groups in term of phenolic acid excretion, as catabolites of (poly)phenolics or colonic metabolism capacity. These same findings, however, highlight important qualitative differences between the two age groups. While all younger participants excreted all 17 phenolic acids in urine after the 3-day high-polyphenols diet, not all older participants excreted the full panel. This varied from one participant excreting 8 out of 17 phenolic acids to another excreting 17 out of 17 phenolic acids. This is particularly relevant as inter-individual variability in the response to (poly)phenolics (including flavonols) is now being increasingly considered [61]. However, whether inter-individual variability of (poly)phenols metabolism suggests a biological difference between the age groups is still unclear.

The phenolic acids consistently seen in urines from both younger and old subjects were BA, MA, 3-OHPAA, HVA, 4-OHMA, 3,4diOHPAA, HA, and 3-OHhippA with 3-OHPAA, HVA, and 3,4diOHPAA, well described rutin metabolites $[27,48]$. Intermediates (3,4-diOHBA, 3,4-diOHPAA, 3,4-diOHPPA) were detected in variable 
Table 4 Accumulation of seven phenolic acids ( $\mu \mathrm{mol} / \mathrm{L}$ ) after 0,6 , and $24 \mathrm{~h}$ of fermentation in faecal fluids from younger $(n=6)$ and older $(n=4)$ groups

\begin{tabular}{|c|c|c|c|c|c|c|c|c|}
\hline \multirow[t]{2}{*}{ Phenolic acid ${ }^{\mathrm{a}}$} & \multirow[t]{2}{*}{ Group } & \multirow[t]{2}{*}{ Substrates } & \multirow{2}{*}{$\begin{array}{l}0 \mathrm{~h} \\
\text { Median }\end{array}$} & \multicolumn{3}{|l|}{$6 \mathrm{~h}$} & \multicolumn{2}{|l|}{$24 \mathrm{~h}$} \\
\hline & & & & IQR $(Q 1-Q 3)$ & Median & IQR $(Q 1-Q 3)$ & Median & IQR $(Q 1-Q 3)$ \\
\hline \multirow[t]{8}{*}{ PAA [59] } & \multirow[t]{4}{*}{ Younger } & Blank & $3.7(n=6 / 6)$ & $3.0-4.0$ & $15.2(n=6 / 6)$ & $6.0-28.1$ & $66.1(n=6 / 6)$ & $46.8-72.2$ \\
\hline & & Raftiline & $2.7(n=6 / 6)$ & $2.9-5.2$ & $8.6(n=6 / 6)$ & $7.4-8.8$ & $6.6(n=6 / 6)$ & $6.9-10.6$ \\
\hline & & Rutin & $3.3(n=6 / 6)$ & $2.3-3.9$ & $6.0(n=6 / 6)$ & $3.5-11.3$ & $81.9(n=6 / 6)$ & $44.4-95.5$ \\
\hline & & Rutin + raftiline & $4.3(n=6 / 6)$ & $2.5-3.2$ & $8.6(n=6 / 6)$ & $5.3-9.8$ & $8.6(n=6 / 6)$ & $3.9-10.1$ \\
\hline & \multirow[t]{4}{*}{ Older } & Blank & $6.9(n=4 / 4)$ & $6.2-7.7$ & $92.8(n=4 / 4)$ & $38.7-138.2$ & $88.8(n=4 / 4)$ & $81.4-101.4$ \\
\hline & & Raftiline & $7.0(n=4 / 4)$ & $4.4-9.5$ & $22.2(n=4 / 4)$ & $15.8-42.1$ & $26.6(n=4 / 4)$ & $18.4-44.7$ \\
\hline & & Rutin & $6.7(n=4 / 4)$ & $4.2-8.8$ & $58.7(n=4 / 4)$ & $12.7-110.8$ & $128.3(n=4 / 4)$ & $93.4-147.3$ \\
\hline & & Rutin + raftiline & $6.4(n=4 / 4)$ & $3.8-8.6$ & $17.5(n=4 / 4)$ & $9.1-42.0$ & $25.3(n=4 / 4)$ & $18.9-40.8$ \\
\hline \multirow{8}{*}{$\begin{array}{l}\text { 3-OHPAA [48, 57, } \\
\text { 59] }\end{array}$} & \multirow[t]{4}{*}{ Younger } & Blank & $0.2(n=1 / 6)$ & - & $0.2(n=1 / 6)$ & - & $0.5(n=2 / 6)$ & $0.4-0.6$ \\
\hline & & Raftiline & $0.3(n=1 / 6)$ & - & $0.2(n=1 / 6)$ & - & $0.1(n=1 / 6)$ & - \\
\hline & & Rutin & $0.2(n=1 / 6)$ & - & $1.5(n=2 / 6)$ & $1.1-2.0$ & $4.4(n=5 / 6)$ & $10.4-24.3$ \\
\hline & & Rutin + raftiline & $0.1(n=1 / 6)$ & - & $1.3(n=1 / 6)$ & - & $1.3(n=2 / 6)$ & $0.9-1.7$ \\
\hline & \multirow[t]{4}{*}{ Older } & Blank & ND & - & $0.1(\mathrm{n}=1 / 4)$ & - & $0.1(n=1 / 4)$ & - \\
\hline & & Raftiline & ND & - & ND & - & ND & - \\
\hline & & Rutin & $0.1(n=1 / 4)$ & - & $0.8(n=2 / 4)$ & $0.5-1.1$ & $4.2(n=3 / 4)$ & $3.2-29.8$ \\
\hline & & Rutin + raftiline & ND & - & $0.3(n=3 / 4)$ & $0.2-1.2$ & $0.6(n=3 / 4)$ & $0.4-0.8$ \\
\hline \multirow[t]{8}{*}{ 4-OHBA [48, 57] } & \multirow[t]{4}{*}{ Younger } & Blank & ND & - & $\mathrm{ND}$ & - & $\mathrm{ND}$ & - \\
\hline & & Raftiline & ND & - & $0.1(n=1 / 6)$ & - & $0.1(n=1 / 6)$ & - \\
\hline & & Rutin & $0.1(n=1 / 6)$ & - & $0.1(n=1 / 6)$ & - & $0.1(n=1 / 6)$ & - \\
\hline & & Rutin + raftiline & ND & - & $0.1(n=1 / 6)$ & - & $0.1(n=1 / 6)$ & - \\
\hline & \multirow[t]{4}{*}{ Older } & Blank & $0.2(n=2 / 4)$ & $0.2-0.2$ & $0.4(n=3 / 4)$ & $0.3-12.2$ & $0.3(n=3 / 4)$ & $0.2-13.8$ \\
\hline & & Raftiline & $0.2(n=1 / 4)$ & - & $0.2(n=1 / 4)$ & - & $0.1(n=1 / 4)$ & - \\
\hline & & Rutin & $0.3(n=2 / 4)$ & $0.1-0.3$ & $0.2(n=2 / 4)$ & $0.1-0.2$ & $0.2(n=2 / 4)$ & $0.1-0.2$ \\
\hline & & Rutin + raftiline & $0.2(n=2 / 4)$ & $0.1-0.2$ & $0.3(n=2 / 4)$ & $0.2-0.2$ & $0.4(n=2 / 4)$ & $0.3-0.4$ \\
\hline \multirow[t]{8}{*}{ 3-ОHРPA [27, 60] } & \multirow[t]{4}{*}{ Younger } & Blank & $1.6(n=2 / 6)$ & $1.2-2.0$ & $2.8(n=3 / 6)$ & $1.6-3.0$ & $2.9(n=3 / 6)$ & $1.7-3.3$ \\
\hline & & Raftiline & $0.5(n=3 / 6)$ & $0.4-1.8$ & $0.9(n=5 / 6)$ & $0.7-1.2$ & $1.3(n=5 / 6)$ & $1.2-2.6$ \\
\hline & & Rutin & $0.4(n=4 / 6)$ & $0.3-1.1$ & $1.8(n=5 / 6)$ & $1.1-1.9$ & $4.8(n=6 / 6)$ & $2.0-10.0$ \\
\hline & & Rutin + raftiline & $0.4(n=3 / 6)$ & $0.4-1.3$ & $1.6(n=4 / 6)$ & $0.5-5.0$ & $1.2(n=5 / 6)$ & $0.8-3.4$ \\
\hline & \multirow[t]{4}{*}{ Older } & Blank & $0.9(n=4 / 4)$ & $0.6-1.7$ & $4.2(n=4 / 4)$ & $0.6-8.2$ & $3.4(n=4 / 4)$ & $2.2-4.9$ \\
\hline & & Raftiline & $1.0(n=4 / 4)$ & $0.6-2.9$ & $2.8(n=4 / 4)$ & $1.0-5.0$ & $3.4(n=4 / 4)$ & $2.7-4.1$ \\
\hline & & Rutin & $0.5(n=4 / 4)$ & $0.4-1.3$ & $7.7(n=4 / 4)$ & $1.6-25.1$ & $13.4(n=4 / 4)$ & $11.7-20.1$ \\
\hline & & Rutin + raftiline & $1.3(n=4 / 4)$ & $0.5-2.3$ & $9.5(n=4 / 4)$ & $1.6-22.4$ & $9.4(n=4 / 4)$ & $3.0-18.9$ \\
\hline \multirow[t]{8}{*}{ 4-ОНРPA [57] } & \multirow[t]{4}{*}{ Younger } & Blank & $0.4(n=2 / 6)$ & $0.3-0.6$ & $6.5(n=4 / 6)$ & $3.6-10.3$ & $1.2(n=4 / 6)$ & $0.8-3.4$ \\
\hline & & Raftiline & $0.6(n=2 / 6)$ & $0.4-0.6$ & $3.8(n=4 / 6)$ & $2.9-4.1$ & $3.9(n=4 / 6)$ & $3.1-4.0$ \\
\hline & & Rutin & $0.5(n=2 / 6)$ & $0.3-0.6$ & $1.1(n=4 / 6)$ & $0.9-1.7$ & $4.9(n=5 / 6)$ & $1.6-7.7$ \\
\hline & & Rutin + raftiline & $0.5(n=1 / 6)$ & - & $1.0(n=3 / 6)$ & $0.9-2.2$ & $1.2(n=3 / 6)$ & $1.0-2.0$ \\
\hline & \multirow[t]{4}{*}{ Older } & Blank & $0.4(n=3 / 4)$ & $0.2-0.8$ & $3.4(n=3 / 4)$ & $1.8-14.6$ & $21.6(n=4 / 4)$ & $10.3-37.6$ \\
\hline & & Raftiline & $0.3(n=3 / 4)$ & $0.2-0.9$ & $1.4(\mathrm{n}=3 / 4)$ & $0.9-1.4$ & $2.0(n=3 / 4)$ & $1.3-2.0$ \\
\hline & & Rutin & $0.8(n=4 / 4)$ & $0.3-1.3$ & $1.6(n=4 / 4)$ & $1.3-2.1$ & $6.9(n=4 / 4)$ & $5.0-14.2$ \\
\hline & & Rutin + raftiline & $0.3(n=3 / 4)$ & $0.2-0.9$ & $0.4(n=3 / 4)$ & $0.4-0.7$ & $1.9(n=3 / 4)$ & $1.4-4.6$ \\
\hline
\end{tabular}


Table 4 (continued)

\begin{tabular}{|c|c|c|c|c|c|c|c|c|}
\hline \multirow[t]{2}{*}{ Phenolic acid ${ }^{\mathrm{a}}$} & \multirow[t]{2}{*}{ Group } & \multirow[t]{2}{*}{ Substrates } & \multirow{2}{*}{$\begin{array}{l}0 \mathrm{~h} \\
\text { Median }\end{array}$} & \multicolumn{3}{|l|}{$6 \mathrm{~h}$} & \multicolumn{2}{|l|}{$24 \mathrm{~h}$} \\
\hline & & & & IQR $(Q 1-Q 3)$ & Median & IQR $(Q 1-Q 3)$ & Median & IQR $(Q 1-Q 3)$ \\
\hline \multirow[t]{8}{*}{ 3,4diOHPAA $[48,59]$} & \multirow[t]{4}{*}{ Younger } & Blank & ND & - & ND & - & ND & - \\
\hline & & Raftiline & ND & - & ND & - & ND & - \\
\hline & & Rutin & ND & - & $16.1(n=6 / 6)$ & $8.7-35.9$ & $32.9(n=6 / 6)$ & $5.5-62.4$ \\
\hline & & Rutin + raftiline & $0.2(n=1 / 6)$ & - & $5.0(n=6 / 6)$ & $1.7-32.1$ & $7.1(n=6 / 6)$ & $2.9-32.9$ \\
\hline & \multirow[t]{4}{*}{ Older } & Blank & $\mathrm{ND}$ & - & ND & - & ND & - \\
\hline & & Raftiline & ND & - & ND & - & $3.2(n=1 / 4)$ & - \\
\hline & & Rutin & $0.3(n=1 / 4)$ & - & $63.0(n=3 / 4)$ & $32.0-66.3$ & $65.8(n=3 / 4)$ & $35.4-79.1$ \\
\hline & & Rutin + raftiline & $0.5(n=1 / 4)$ & - & $48.3(n=3 / 4)$ & $24.8-48.7$ & $52.0(n=3 / 4)$ & $27.1-53.0$ \\
\hline \multirow[t]{8}{*}{ 3,4diOHPPA [59] } & \multirow[t]{4}{*}{ Younger } & Blank & $\mathrm{ND}$ & - & $\mathrm{ND}$ & - & $\mathrm{ND}$ & - \\
\hline & & Raftiline & ND & - & ND & - & ND & - \\
\hline & & Rutin & ND & - & $0.2(n=1 / 6)$ & - & $0.4(n=2 / 6)$ & $0.4-0.5$ \\
\hline & & Rutin + raftiline & $\mathrm{Nd}$ & - & ND & - & ND & - \\
\hline & \multirow[t]{4}{*}{ Older } & Blank & $\mathrm{Nd}$ & - & ND & - & ND & - \\
\hline & & Raftiline & $\mathrm{Nd}$ & - & ND & - & ND & - \\
\hline & & Rutin & $0.2(n=1 / 4)$ & - & $1.1(n=2 / 4)$ & $0.5-1.6$ & $0.5(n=2 / 4)$ & $0.4-0.4$ \\
\hline & & Rutin + raftiline & ND & - & ND & - & $0.6(n=1 / 4)$ & - \\
\hline
\end{tabular}

PAA phenylacetic acid; 3-OHPAA 3-hydroxyphenylacetic acid; 3-OHPPA 3-hydroxyphenylpropionic acid; 4-OHBA 4-hydroxybenzoic acid; 4-OHPPA 4-hydroxyphenylpropionic acid; 3,4diOHPAA 3, 4-dihydroxyphenylacetic acid; 3,4diOHPPA 4-hydroxy-3-methoxy-phenylpropionic acid; $N D$ not detected

${ }^{a}$ Phenolic acids previously described in the literature

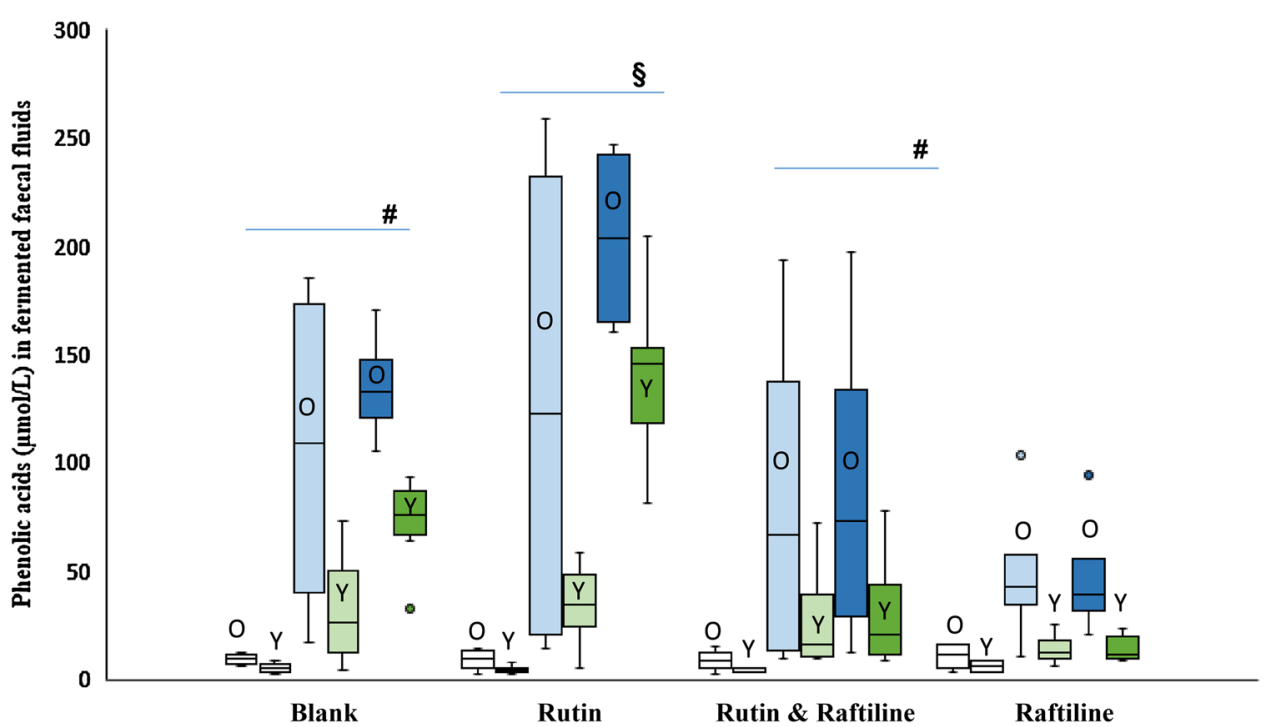

Fig. 4 Sum of all $(n=7)$ phenolic acids $(\mu \mathrm{mol} / \mathrm{L})$ in fermented faecal fluids from older $(n=4)$ and younger $(n=6)$ adults (over $24 \mathrm{~h}$ of fermentation). The white boxes represent $t=0 \mathrm{~h}$, the light shaded boxes $t=6 \mathrm{~h}$ and the dark shaded boxes, $t=24 \mathrm{~h}$. Boxes representing the older group are labelled "O", boxes representing the younger group

amounts at different time points, but the absence of these phenolic acids at any given point does not simply illustrate capacity, but also the kinetics in flavonol catabolism. The evidence in this study and that of others is are labelled "Y". \#There was a statistically significant increase in the sum of PA in younger adults over time in the blank fermentations $(p<0.001)$ and when rutin and raftiline were combined $(p=0.001) . \S$ There was a statistically significant increase in the sum of PA in older adults over time in the fermentations with rutin alone $(p=0.04)$

clearest 3-OHPAA and 3,4-diOHPAA, as they are both found in the in vivo and in vitro studies. Three more, HVA, 3,4-diOHPPA, and 3-OHhippA were present in the in vivo study after the HPD in both age groups, but not in 
the in vitro fermentations-highlighting the likely role of phase II metabolism in the liver in the synthesis of these compounds. However, VA, GA, 4-OHMA, 3,4-diOHBA which were present in all younger participants, but only in some of the older participants, could be linked to agerelated variations.

With their simpler structure and increased bioavailability, phenolic acids are one of the major (poly)phenol metabolites present in blood with a maximum plasma concentration of $0-4 \mu \mathrm{mol} / \mathrm{L}$ with an intake of $50 \mathrm{mg}$ aglycone equivalents [62], and reported anti-inflammatory, anti-carcinogenic, anti-proliferative, anti-glycative and prebiotic properties in in vitro and/or in vivo studies [16, 62-65]. As the concentration in the colon is much higher than in the circulation with concentration ranging from 46 to $479 \mu \mathrm{mol} / \mathrm{L}$ in human faecal water [59, 66], some effects exerted at high doses may still be physiological [67]. Moreover, while phenolic acid intake is usually in the range of 50-900 mg per day, phenolic acids in urines can reach levels close to $1 \mathrm{mmol} /$ day - as urinary phenolic acid largely come from the colonic metabolism of (poly) phenolics, but also other compounds such as benzoic acid and precursors (quinic acid, aromatic amino acid tryptophan, tyrosine, and phenylalanine). Other sources of benzoic acid are benzoates (E numbers 210-219) which are commonly used in food, medications, and mouthwashes $[68,69]$.

The bioactivity of specific phenolic acids is less well defined, with examples including 3,4diOHPAA an inhibitor of enzymes involved in detoxification (GSTT2), inflammation (COX-2) and anti-proliferative activity in HCT116 colon cancer cells $[67,70]$; 3,4-diOHPPA $(3 \mu \mathrm{M})$ and 3,4-diOHPAA $(3 \mu \mathrm{M})$, inhibitors of the pro-inflammatory cytokines such as TNF-a, IL-1b and IL-6 in lipopolysaccharide-stimulated peripheral blood mononuclear cells [70, 71]; and gallic acid $(882 \mu \mathrm{M})$ inhibitor of Clostridium histolyticum in in vitro faecal fermentation [65, 72].

The intra-group variation we observed could be due to the variation in gut microbiota, themselves influenced by genetics, lifestyle, diet and ageing. Older adults excreted a higher amount of hippuric acid in their urine. Hippuric acid is formed in the liver by conjugation of colonic benzoic acids with glycine; therefore, the high amount of HA could come from sources other than (poly)phenol-rich food metabolism, such as amino acids [68, 69]. Moreover, urinary hippuric acid correlated with hypertension and obesity [73, 74], which would be consistent with the characteristics of some in our older group. The high intra-group variability within the older group for the sum of the phenolic acids was mainly attributable for hippuric acid (30-fold difference between low and high excreters); however, the variability reduced to only threefold when hippuric acid was not included in the sum of phenolic acids.
Several potential mechanisms could explain the absence of some of the phenolic acids in the urine of participants as well as the low amount of phenolic acid excreted in the urine of the older group.

The first mechanism involves a decrease in colonic absorption. As the individual ages, colonic absorption is reduced and the mucosal surface area is diminished [75, 76]. During in vitro faecal fermentation of rutin, a high amount of PAA was detected in the faeces-only control at $0 \mathrm{~h}$ in the older group, suggesting that bacterial phenolic metabolism is not the sole source of increased PAA. The comparatively greater formation of PAA in the fermentation fluid of the older participants in the presence of rutin may also point toward a higher capacity of faecal material from older participants to effectively metabolise rutin with the low urinary phenolic acid excretion due to poorer absorption of the phenolic compounds in the colon. Variability in enterohepatic (re)circulation is not well studied and could be an additional contributing factor [77].

The second mechanism relates to the effect of ageing on the colonic microbiota composition and associated microbial and enzymatic activities. In the human colon, bacterial enzymes ( $\beta$-glucosidases, $\beta$-glucuronidases, and $\alpha$-rhamnosidase) hydrolyse rutin to release the quercetin aglycone [78]. Insufficient or lower levels of bacterial enzymes in the colon could be one reason for the absence and low urinary phenolic acid in the older group. Although these bacterial enzymes were not measured directly in this present study, we could not detect a difference between groups in the quantity of bifidobacteria, bacteroides, or Flavonifractor plautii bacteria. The aim of the current protocol focusing on targeted bacteria was not to study the impact of dietary components, but instead to establish how pre-HPD levels of these bacteria could factor in the differences in phenolic acid excretion. Selected bacteria were measured in representative faecal samples and the values were not corrected for the total amount of daily faecal output, which could affect the accuracy of the measurement. Indeed, as the bacteria measurements were performed after the lowpolyphenol diet which was lower (but not devoid of) in fibre (younger: $9 \mathrm{~g} /$ day; older: $12 \mathrm{~g} /$ day), with a view to describe the levels of the targeted bacteria before exposure to the HPD. It is not clear how fibre intake impacts, short term (here, 3 days) on bacterial diversity and total numbers. Additionally, the selected bacteria measured in this study may not be representative of all bacteria responsible for (poly)phenol metabolism found in the colon such as Enterococcus casseliflavus [53, 79] Butyrivibrio spp. [80], and Bacteroides distasonis [58], and may have been influenced by the nutrients in the low-polyphenolic diet (although the impact of such a short-term intervention on bacterial populations themselves is not clear). Based on this study's finding, the differences in colonic fermentation between groups, as 
modeled in vitro, are unlikely to be linked to the differences seen in the urinary phenolic acid excretion between groups. Woodmansey et al. [81] reported that a high faecal $\mathrm{pH}$ in the elderly (due to a low fibre intake) may lead to a reduction in SCFA production. In the present study, faecal $\mathrm{pH}$ was close to 8.0 in the older group after the LPD and above 7.0 after the HPD. However, even though the SCFA were higher in the older group after the HPD, there were no differences between groups when considering the change from the low to high-polyphenol diet. As mentioned above, the measurement of the SCFA was performed in a representative faecal sample and correction for the total daily faecal output was not possible. A pH above 7.0 could be due to other compounds such as ammonia, which have been reported in older adults [81], either due to lower fibre intake and/or increased activity of proteolytic bacterial species, such as Fusobacteria, Propionibacteria, and Clostridia.

It is important when studying the bioavailability of bioactive molecules to consider stratification of the population into responders and non-responders. Age and other factors such as gender, genetics, gut microbiota or physiological status involved in creating inter-individual variability are important to consider before developing such stratification models. Improvement in the knowledge of factors such as age, gender, genetic and gut microbiota composition, and their influence on the metabolism of plant food bioactive molecules, together with the development of methods to identify responsiveness profiles will enhance the development of effective and innovative products for prevention of chronic disease [82]. The strength of this study includes the combination of in vivo and in vitro designs to assess the colonic bacterial metabolic ability of each group. However, the full profile of (poly)phenol metabolites was not measured in the urine and the phenolic acids were not measured in faecal samples, which could have provided useful information regarding the absorption and accumulation of the phenolic compounds in the colon. Only selected bacterial species were measured in the faecal samples, and other gut bacteria such as, Clostridium scindens, Eubacterium desmolans, Eubacterium ramulus [52, 60, 79, 83], Butyrivibrio sp [80], and Bacteroides distasonis [58] could potentially contribute to the colonic metabolism of dietary (poly)phenols.

The differential excretion of phenolic acids in older adults may be linked to differences in the gut microbiota profile or functionality, but may also be linked to other gastrointestinal factors. Age was shown to impact on the phenolic acid profiles excreted in urine between groups qualitatively, as well as quantitatively (the younger group excreted higher phenolic acid in urine after both low- and high-polyphenolic diets). These differences were not explained by the in vitro fermentations, as a similar range of phenolic acids was formed from the substrates in both groups, with minimal quantitative differences. Our study highlights the importance of study participant selection (and description) in experimental design aiming to explore the colonic metabolism of plant bioactives. Age may be a factor influencing the considerable variance in measurements seen in some studies. The restricted urinary phenolic acid profile observed in some participants in the older group may have relevance for colonic health, and should be investigated further.

Open Access This article is distributed under the terms of the Creative Commons Attribution 4.0 International License (http://creativeco mmons.org/licenses/by/4.0/), which permits unrestricted use, distribution, and reproduction in any medium, provided you give appropriate credit to the original author(s) and the source, provide a link to the Creative Commons license, and indicate if changes were made.

\section{References}

1. World Health Organization. World report on ageing and health. World Health Organization, Geneva

2. Cracknell R (2010) The aging population. House of Commons Library Research, London

3. Gavini F, Cayuela C, Antoine J-M, Lecoq C, Lefebvre B, Membre J-M, Neut C (2001) Differences in the distribution of bifidobacterial and enterobacterial species in human faecal microflora of three different (children, adults, elderly) age groups. Microb Ecol Health Dis 13(1):40-45

4. Rowland IR (2009) The role of the gastrointestinal microbiota in colorectal cancer. Curr Pharm Design 15:1524-1527

5. Tremaroli V, Bäckhed F (2012) Functional interactions between the gut microbiota and host metabolism. Nature 489(7415):242249. https://doi.org/10.1038/nature 11552

6. Donohoe DR, Garge N, Zhang X, Sun W, O'Connell TM, Bunger MK, Bultman SJ (2011) The microbiome and butyrate regulate energy metabolism and autophagy in the mammalian colon. Cell Metab 13(5):517-526. https://doi.org/10.1016/j.cmet.2011.02.018

7. Fung KYC, Brierley GV, Henderson S, Hoffmann P, McColl SR, Lockett T, Head R, Cosgrove L (2011) Butyrate-induced apoptosis in HCT116 colorectal cancer cells includes induction of a cell stress response. J Proteome Res 10(4):1860-1869. https://doi. org/10.1021/pr1011125

8. Hamer HM, Jonkers D, Venema K, Vanhoutvin S, Troost FJ, Brummer RJ (2008) Review article: the role of butyrate on colonic function. Aliment Pharmacol Ther 27(2):104-119. https://doi.org /10.1111/j.1365-2036.2007.03562.x

9. MacDonald R, Wagner K (2012) Influence of dietary phytochemicals and microbiota on colon cancer risk. J Agric Food Chem 60(27):6728-6735. https://doi.org/10.1021/jf204230r

10. Linseisen J, Rohrmann S (2008) Biomarkers of dietary intake of flavonoids and phenolic acids for studying diet-cancer relationship in humans. Eur J Nutr 47:60-68. https://doi.org/10.1007/s0039 4-008-2007-x

11. Fernandez-Millan E, Ramos S, Alvarez C, Bravo L, Goya L, Angeles Martin M (2014) Microbial phenolic metabolites improve glucose-stimulated insulin secretion and protect pancreatic beta cells against tert-butyl hydroperoxide-induced toxicity via ERKs and PKC pathways. Food Chem Toxicol 66:245-253. https://doi. org/10.1016/j.fct.2014.01.044

12. Guan F, Liu AB, Li G, Yang Z, Sun Y, Yang CS, Ju J (2012) Deleterious effects of high concentrations of (-)-epigallocatechin-3-gallate and atorvastatin in mice with colon inflammation. 
Nutr Cancer 64(6):847-855. https://doi.org/10.1080/01635 581.2012 .695424

13. Wang LS, Burke CA, Hasson H, Kuo CT, Molmenti CLS, Seguin C, Liu PY, Huang THM, Frankel WL, Stoner GD (2014) A phase Ib study of the effects of black raspberries on rectal polyps in patients with familial adenomatous polyposis. Cancer Prev Res 7(7):666-674. https://doi.org/10.1158/1940-6207.capr-14-0052

14. Little CH, Combet E, McMillan DC, Horgan PG, Roxburgh CS (2015) The role of dietary polyphenols in the moderation of the inflammatory response in early stage colorectal cancer. Crit Rev Food Sci Nutr. https://doi.org/10.1080/10408398.2014.997866

15. Gibson GR, Hutkins R, Sanders ME, Prescott SL, Reimer RA, Salminen SJ, Scott K, Stanton C, Swanson KS, Cani PD, Verbeke K, Reid G (2017) Expert consensus document: the international scientific association for probiotics and prebiotics (ISAPP) consensus statement on the definition and scope of prebiotics. Nat Rev Gastroenterol Hepatol. https://doi.org/10.1038/nrgas tro.2017.75

16. Tzounis X, Rodriguez-Mateos A, Vulevic J, Gibson GR, KwikUribe C, Spencer JPE (2011) Prebiotic evaluation of cocoaderived flavanols in healthy humans by using a randomized, controlled, double-blind, crossover intervention study. Am J Clin Nutr 93(1):62-72. https://doi.org/10.3945/ajcn.110.000075

17. Boto-Ordóñez M, Urpi-Sarda M, Queipo-Ortuño MI, Tulipani S, Tinahones FJ, Andres-Lacueva C (2014) High levels of Bifidobacteria are associated with increased levels of anthocyanin microbial metabolites: a randomized clinical trial. Food Funct 5(8):1932-1938. https://doi.org/10.1039/c4fo00029c

18. Bialonska D, Kasimsetty SG, Schrader KK, Ferreira D (2009) The effect of pomegranate (Punica granatum $\mathrm{L}$.) byproducts and ellagitannins on the growth of human GUT bacteria. J Agric Food Chem 57(18):8344-8349. https://doi.org/10.1021/jf901931b

19. Nohynek LJ, Alakomi HL, Kahkonen MP, Heinonen M, Helander KM, Oksman-Caldentey KM, Puupponen-Pimia RH (2006) Berry phenolics: antimicrobial properties and mechanisms of action against severe human pathogens. Nutr Cancer 54(1):18-32

20. Bub A, Watzl B, Blockhaus M, Briviba K, Liegibel U, Muller H, Pool-Zobel BL, Rechkemmer G (2003) Fruit juice consumption modulates antioxidative status, immune status and DNA damage. J Nutr Biochem 14(2):90-98

21. Rechner A, Wagner E, Van Buren L, Van de Put F, Wiseman S, Rice-Evans C (2002) Black tea represents a major source of dietary phenolics among regular tea drinkers. Free Radical Res 36(10):1127-1135. https://doi.org/10.1080/107157602100000 6707

22. Jaganath I, Mullen W, Edwards C, Crozier A (2006) The relative contribution of the small and large intestine to the absorption and metabolism of rutin in man. Free Radical Res 40(10):1035-1046. https://doi.org/10.1080/10715760600771400

23. Olthof M, Hollman P, Buijsman M, van Amelsvoort J, Katan M (2003) Chlorogenic acid, quercetin-3-rutinoside and black tea phenols are extensively metabolized in humans. J Nutr 133(6):1806-1814

24. Mullen W, Edwards C, Crozier A (2006) Absorption, excretion and metabolite profiling of methyl-, glucuronyl-, glucosyland sulpho-conjugates of quercetin in human plasma and urine after ingestion of onions. Br J Nutr 96(1):107-116. https://doi. org/10.1079/BJN20061809

25. Vitaglione P, Lumaga RB, Ferracane R, Sellitto S, Morello JR, Miranda JR, Shimoni E, Fogliano V (2013) Human bioavailability of flavanols and phenolic acids from cocoa-nut creams enriched with free or microencapsulated cocoa polyphenols. Br J Nutr 109(10):1832-1843. https://doi.org/10.1017/s0007114512003881

26. Iswaldi I, Arraez-Roman D, Gomez-Caravaca AM, Contreras MD, Uberos J, Segura-Carretero A, Fernandez-Gutierrez A (2013) Identification of polyphenols and their metabolites in human urine after cranberry-syrup consumption. Food Chem Toxicol 55:484-492. https://doi.org/10.1016/j.fct.2013.01.039

27. Gross G, Jacobs D, Peters S, Possemiers S, van Duynhoven J, Vaughan E, van de Wiele T (2010) In vitro bioconversion of polyphenols from black tea and red wine/grape juice by human intestinal microbiota displays strong interindividual variability. J Agric Food Chem 58(18):10236-10246. https://doi.org/10.1021/ jf $101475 \mathrm{~m}$

28. Gill C, McDougall G, Glidewell S, Stewart D, Shen Q, Tuohy K, Dobbin A, Boyd A, Brown E, Haldar S, Rowland I (2010) Profiling of phenols in human fecal water after raspberry supplementation. J Agric Food Chem 58(19):10389-10395. https:// doi.org/10.1021/jf1017143

29. Gardana C, Canzi E, Simonetti P (2009) The role of diet in the metabolism of daidzein by human faecal microbiota sampled from Italian volunteers. J Nutr Biochem 20(12):940-947. https://doi. org/10.1016/j.jnutbio.2008.08.006

30. Fuhr U, Kummert AL (1995) The fate of naringin in humans: a key to grapefruit juice-drug interactions? Clin Pharmacol Ther 58(4):365-373. https://doi.org/10.1016/0009-9236(95)90048-9

31. Roowi S, Stalmach A, Mullen W, Lean M, Edwards C, Crozier A (2010) Green tea flavan-3-ols: colonic degradation and urinary excretion of catabolites by humans. J Agric Food Chem 58(2):1296-1304. https://doi.org/10.1021/jf9032975

32. Borel P, Desmarchelier C, Nowicki M, Bott R, Morange S, Lesavre N (2014) Interindividual variability of lutein bioavailability in healthy men: characterization, genetic variants involved, and relation with fasting plasma lutein concentration. Am J Clin Nutr 100(1):168-175. https://doi.org/10.3945/ajcn.114.085720

33. Tomás-Navarro M, Vallejo F, Sentandreu E, Navarro JL, TomásBarberán FA (2014) Volunteer stratification is more relevant than technological treatment in orange juice flavanone bioavailability. $\mathrm{J}$ Agric Food Chem 62(1):24-27. https://doi.org/10.1021/jf4048989

34. Rodriguez-Mateos A, Cifuentes-Gomez T, Gonzalez-Salvador I, Ottaviani JI, Schroeter H, Kelm M, Heiss C, Spencer JP (2015) Influence of age on the absorption, metabolism, and excretion of cocoa flavanols in healthy subjects. Mol Nutr Food Res 59(8):1504-1512. https://doi.org/10.1002/mnfr.201500091

35. Madsen J, Graff J (2004) Effects of ageing on gastrointestinal motor function. Age Ageing 33(2):154-159

36. Camilleri $M(2000)$ Insights into the pathophysiology and mechanisms of constipation, irritable bowel syndrome, and diverticulosis in older people. J Am Geriatr Soc 48(9):1142-1150

37. Madsen JL (1992) Effects of gender, age, and body mass index on gastrointestinal transit times. Dig Dis Sci 37(10):1548-1553

38. Firth M, Prather C (2002) Gastrointestinal motility problems in the elderly patient. Gastroenterology 122(6):1688-1700

39. Madsen J (1992) Effects of gender, age, and body-mass index on gastrointestinal transit times. Dig Dis Sci 37(10):1548-1553

40. Brodeur J (1993) Nutrient intake and gastrointestinal disorders related to masticatory performance in the edentulous elderly. $\mathrm{J}$ Prosthet Dent 70(5):468-473

41. Wijhuizen G, de Jong R, Hopman-Rock M (2007) Older persons afraid of falling reduce physical activity to prevent outdoor falls. Prev Med 44(3):260-264

42. ISD Scotland. Scottish Bowel Screening Programme (2014). http://www.isdscotland.org/Health-Topics/Cancer/BowelScree ning/. Accessed 21 Nov 2014

43. Combet E, Lean M, Boyle J, Crozier A, Davidson D (2011) Dietary flavonols contribute to false-positive elevation of homovanillic acid, a marker of catecholamine-secreting tumors. Clin Chim Acta 412(1-2):165-169. https://doi.org/10.1016/j. cca.2010.09.037

44. Lohman T, Roche A, Martorell R (1988) Anthropometric standardization reference manual. Human Kinetics Books, Champaign 
45. Wise A (2008) Developments in nutritional programming illustrated by WinDiets. Nutr Bull 33(1):55-57. https://doi.org/10.11 11/j.1467-3010.2007.00660.x

46. Neveu V, Perez-Jiménez J, Vos F, Crespy V, du Chaffaut L, Mennen L, Knox C, Eisner R, Cruz J, Wishart D, Scalbert A (2010) Phenol-Explorer: an online comprehensive database on polyphenol contents in foods. Database (Oxford) 2010:bap024. https:// doi.org/10.1093/database/bap024

47. Chlopicka J, Pasko P, Gorinstein S, Jedryas A, Zagrodzki P (2012) Total phenolic and total flavonoid content, antioxidant activity and sensory evaluation of pseudocereal breads. Lwt-Food Sci Technol 46(2):548-555. https://doi.org/10.1016/j.lwt.2011.11.009

48. Jaganath I, Mullen W, Lean M, Edwards C, Crozier A (2009) In vitro catabolism of rutin by human fecal bacteria and the antioxidant capacity of its catabolites. Free Radic Biol Med 47(8):1180 1189. https://doi.org/10.1016/j.freeradbiomed.2009.07.031

49. Stalmach A, Edwards C, Wightman J, Crozier A (2013) Colonic catabolism of dietary phenolic and polyphenolic compounds from concord grape juice. Food Funct 4(1):52-62. https://doi. org $/ 10.1039 / \mathrm{c} 2$ fo $30151 \mathrm{~b}$

50. Laurentin A, Edwards CA (2004) Differential fermentation of glucose-based carbohydrates in vitro by human faecal bacteriaa study of pyrodextrinised starches from different sources. Eur J Nutr 43(3):183-189. https://doi.org/10.1007/s00394-004-0457-3

51. Gerasimidis K (2009) Nutritional aspects and gut microbiota in paediatric. Inflammatory Bowel Disease University of Glasgow, Glasgow

52. Braune A, Gutschow M, Engst W, Blaut M (2001) Degradation of quercetin and luteolin by Eubacterium ramulus. Appl Environ Microbiol 67(12):5558-5567. https://doi.org/10.1128/ AEM.67.12.5558-5567.2001

53. Schneider H, Blaut M (2000) Anaerobic degradation of flavonoids by Eubacterium ramulus. Arch Microbiol 173(1):71-75. https:// doi.org/10.1007/s002030050010

54. Simmering R, Pforte H, Jacobasch G, Blaut M (2002) The growth of the flavonoid-degrading intestinal bacterium, Eubacterium ramulus, is stimulated by dietary flavonoids in vivo. Fems Microbiology Ecology 40(3):243-248. https://doi. org/10.1111/j.1574-6941.2002.tb00957.x

55. Heim N, Snijder MB, Heymans MW, Deeg DJ, Seidell JC, Visser M (2010) Exploring cut-off values for large waist circumference in older adults: a new methodological approach. J Nutr Health Aging 14(4):272-277

56. Heim N, Snijder MB, Heymans MW, Deeg DJH, Seidell JC, Visser M (2011) Optimal cutoff values for high-risk waist circumference in older adults based on related health outcomes. Am J Epidemiol 174(4):479-489. https://doi.org/10.1093/aje/kwr093

57. Grün $\mathrm{CH}$, van Dorsten FA, Jacobs DM, Le Belleguic M, van Velzen EJ, Bingham MO, Janssen HG, van Duynhoven JP (2008) GC-MS methods for metabolic profiling of microbial fermentation products of dietary polyphenols in human and in vitro intervention studies. J Chromatogr B Analyt Technol Biomed Life Sci 871(2):212-219. https://doi.org/10.1016/j.jchromb.2008.04.039

58. Bokkenheuser VD, Shackleton CH, Winter J (1987) Hydrolysis of dietary flavonoid glycosides by strains of intestinal Bacteroides from humans. Biochem J 248(3):953-956

59. Jenner AM, Rafter J, Halliwell B (2005) Human fecal water content of phenolics: the extent of colonic exposure to aromatic compounds. Free Radic Biol Med 38(6):763-772. https://doi. org/10.1016/j.freeradbiomed.2004.11.020

60. Schoefer L, Mohan R, Schwiertz A, Braune A, Blaut M (2003) Anaerobic degradation of flavonoids by Clostridium orbiscindens. Appl Environ Microbiol 69(10):5849-5854. https://doi. org/10.1128/AEM.69.10.5849-5854.2003

61. Menezes R, Rodriguez-Mateos A, Kaltsatou A, González-Sarrías A, Greyling A, Giannaki C, Andres-Lacueva C, Milenkovic D,
Gibney ER, Dumont J, Schär M, Garcia-Aloy M, Palma-Duran SA, Ruskovska T, Maksimova V, Combet E, Pinto P (2017) Impact of flavonols on cardiometabolic biomarkers: a meta-analysis of randomized controlled human trials to explore the role of inter-individual variability. Nutrients. https://doi.org/10.3390/ nu9020117

62. Manach C, Williamson G, Morand C, Scalbert A, Remesy C (2005) Bioavailability and bioefficacy of polyphenols in humans. I. Review of 97 bioavailability studies. Am J Clin Nutr 81(1):230S-242S

63. Vlassopoulos A, Lean MEJ, Combet E (2014) Protein-phenolic interactions and inhibition of glycation-combining a systematic review and experimental models for enhanced physiological relevance. Food Funct 5(10):2646-2655. https://doi.org/10.1039/ c4fo00568f

64. Rodriguez-Ramiro I, Ramos S, Lopez-Oliva E, Agis-Torres A, Bravo L, Goya L, Martin MA (2013) Cocoa polyphenols prevent inflammation in the colon of azoxymethane-treated rats and in TNF-alpha-stimulated Caco-2 cells. Br J Nutr 110(2):206-215. https://doi.org/10.1017/s0007114512004862

65. Hidalgo M, Martin-Santamaria S, Recio I, Sanchez-Moreno C, de Pascual-Teresa B, Rimbach G, de Pascual-Teresa S (2012) Potential anti-inflammatory, anti-adhesive, anti/estrogenic, and angiotensin-converting enzyme inhibitory activities of anthocyanins and their gut metabolites. Genes Nutr 7(2):295-306. https:// doi.org/10.1007/s12263-011-0263-5

66. Scalbert A, Williamson G (2000) Dietary intake and bioavailability of polyphenols. J Nutr 130(8):2073S-2085S

67. Henning S, Wang P, Abgaryan N, Vicinanza R, de Oliveira D, Zhang Y, Lee R, Carpenter C, Aronson W, Heber D (2013) Phenolic acid concentrations in plasma and urine from men consuming green or black tea and potential chemopreventive properties for colon cancer. Mol Nutr Food Res 57(3):483-492. https://doi. org/10.1002/mnfr.201200646

68. Self HL, Brown RR, Price JM (1960) Quantitative studies on the metabolites of tryptophan in the urine of swine. J Nutr 70:21-25

69. Grümer HD (1961) Formation of hippuric acid from phenylalanine labelled with carbon-14 in phenylketonuric subjects. Nature 189(4758):63

70. Cardona F, Andres-Lacueva C, Tulipani S, Tinahones FJ, Isabel Queipo-Ortuno M (2013) Benefits of polyphenols on gut microbiota and implications in human health. J Nutr Biochem 24(8):1415-1422. https://doi.org/10.1016/j.jnutbio.2013.05.001

71. Monagas M, Khan N, Andrés-Lacueva C, Urpí-Sardá M, VázquezAgell M, Lamuela-Raventós RM, Estruch R (2009) Dihydroxylated phenolic acids derived from microbial metabolism reduce lipopolysaccharide-stimulated cytokine secretion by human peripheral blood mononuclear cells. Br J Nutr 102(2):201-206. https://doi.org/10.1017/S0007114508162110

72. Hidalgo M, Oruna-Concha MJ, Kolida S, Walton GE, Kallithraka S, Spencer JP, de Pascual-Teresa S (2012) Metabolism of anthocyanins by human gut microflora and their influence on gut bacterial growth. J Agric Food Chem 60(15):3882-3890. https://doi. org/10.1021/jf3002153

73. Holmes E, Loo RL, Stamler J, Bictash M, Yap IKS, Chan Q, Ebbels T, De Iorio M, Brown IJ, Veselkov KA, Daviglus ML, Kesteloot H, Ueshima H, Zhao L, Nicholson JK, Elliott P (2008) Human metabolic phenotype diversity and its association with diet and blood pressure. Nature 453(7193):396-U350. https://doi. org/10.1038/nature06882

74. Calvani R, Miccheli A, Capuani G, Tomassini Miccheli A, Puccetti C, Delfini M, Iaconelli A, Nanni G, Mingrone G (2010) Gut microbiome-derived metabolites characterize a peculiar obese urinary metabotype. Int J Obes (Lond) 34(6):1095-1098. https:// doi.org/10.1038/ijo.2010.44 
75. Holt PR, Kotler DP, Yeh KY (1989) Age related increase of brush border enzyme activities along the small intestine. Gut 30(6):887-888

76. Montgomery RD, Haeney MR, Ross IN, Sammons HG, Barford AV, Balakrishnan S, Mayer PP, Culank LS, Field J, Gosling P (1978) The ageing gut: a study of intestinal absorption in relation to nutrition in the elderly. Q J Med 47(186):197-211

77. Aura A-M (2008) Microbial metabolism of dietary phenolic compounds in the colon. Phytochem Rev 7(3):407-429. https://doi. org/10.1007/s11101-008-9095-3

78. Aura A, O'Leary K, Williamson G, Ojala M, Bailey M, Puupponen-Pimia R, Nuutila A, Oksman-Caldentey K, Poutanen K (2002) Quercetin derivatives are deconjugated and converted to hydroxyphenylacetic acids but not methylated by human fecal flora in vitro. J Agric Food Chem 50(6):1725-1730. https://doi. org/10.1021/jf0108056

79. Schneider H, Schwiertz A, Collins M, Blaut M (1999) Anaerobic transformation of quercetin-3-glucoside by bacteria from the human intestinal tract. Arch Microbiol 171(2):81-91. https://doi. org/10.1007/s002030050682

80. Krishnamurty HG, Cheng KJ, Jones GA, Simpson FJ, Watkin JE (1970) Identification of products produced by the anaerobic degradation of rutin and related flavonoids by Butyrivibrio sp. C3. Can J Microbiol 16(8):759-767

81. Woodmansey EJ, McMurdo ME, Macfarlane GT, Macfarlane S (2004) Comparison of compositions and metabolic activities of fecal microbiotas in young adults and in antibiotictreated and non-antibiotic-treated elderly subjects. Appl Environ Microbiol 70(10):6113-6122. https://doi.org/10.1128/ AEM.70.10.6113-6122.2004

82. Manach C, Milenkovic D, Van de Wiele T, Rodriguez-Mateos A, de Roos B, Garcia-Conesa MT, Landberg R, Gibney ER, Heinonen M, Tomás-Barberán F, Morand C (2017) Addressing the inter-individual variation in response to consumption of plant food bioactives: towards a better understanding of their role in healthy aging and cardiometabolic risk reduction. Mol Nutr Food Res 61 (6). https://doi.org/10.1002/mnfr.201600557

83. Simmering R, Kleessen B, Blaut M (1999) Quantification of the flavonoid-degrading bacterium Eubacterium ramulus in human fecal samples with a species-specific oligonucleotide hybridization probe. Appl Environ Microbiol 65(8):3705-3709 